\section{Illumina, PacBio deal dead}

Illumina and Pacific Biosciences announced the mutual termination of their $\$ 1.2$ billion merger agreement, more than a year after it was announced in November 2018. As the chances of a successful outcome dwindled in the face of a long regulatory approval process by the UK's Competition and Markets Authority and US Federal Trade Commission, the Californiabased sequencing companies decided to terminate the agreement in the best interest of their respective shareholders and employees. "When a monopolist buys a potential rival, it can harm competition," said Gail Levine, deputy director of the FTC's competition bureau in a December 2019 statement. The FTC ordered an administrative trial on the deal and authorized staff to seek a restraining order in federal court if necessary to prevent the deal from going through until a resolution was reached. Less than a month later, the deal was dead. Francis deSouza, president and CEO of Illumina, said in a statement, "We believe this proposed combination would have broadened access to Pacific Biosciences sequencing technology, significantly expanded and accelerated innovation, and ultimately increased the clinical utility and impact of sequencing." PacBio president and CEO Michael Hunkapiller said, "We are disappointed that our customers and other stakeholders will not realize the powerful advantages of integrating the sequencing capabilities of our two companies." In accordance with the merger agreement, Illumina will pay PacBio a termination fee of $\$ 98$ million.

Published online: 7 February 2020 https://doi.org/10.1038/s41587-020-0429-z

\footnotetext{
66 "[China] just created a large cell-culture dish in which all these people will share the infection and create a lot more cases all stuck in Wuhan." Ian Mackay, of the University of Queensland, Australia, speaking of the Chinese government's decision to quarantine $>20$ million citizens in cities experiencing the 2019-nCoV coronavirus outbreak. (Nature, 23 January 2020)

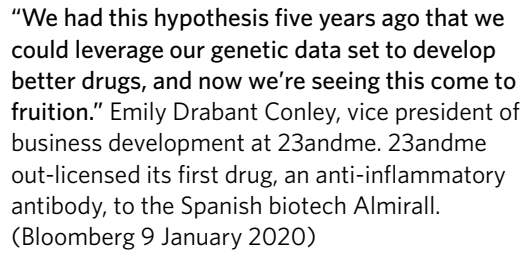
could leverage our genetic data set to develop better drugs, and now we're seeing this come to fruition." Emily Drabant Conley, vice president of business development at 23andme. 23andme out-licensed its first drug, an anti-inflammatory antibody, to the Spanish biotech Almirall. (Bloomberg 9 January 2020)

University in California, is advising Cygnal and is not involved in Divide \& Conquer.)

The Medicxi-backed startup is broadly focused on targeting "the connections that the tumor cells make with each other and with the surrounding normal tissue," says executive chairman and cofounder David Grainger. In glioblastoma, Divide \& Conquer's top therapeutic priority, those connections are between cancer cells and neurons. With its lead smallmolecule candidate, the company aims to block the signaling pathway involved in activating growth-associated protein-43, a crucial regulator of synaptic plasticity that Winkler has found is also essential to the formation and function of tumor protrusions. A phase 1 trial is anticipated for early 2021.

Cells from other types of cancer form connections with cells other than neurons, though. In triple-negative breast cancer, for example, Divide \& Conquer has unpublished data showing that the intercellular exchanges driving tumor aggressiveness and therapeutic resistance occur between malignant cells and surrounding fibroblasts, Grainger says. And the company is also looking to sever the ties that bind pancreatic cancer, a disease recently shown by cell biologist Henry Higgs of the Dartmouth College Geisel School of Medicine in Hanover, New Hampshire, who is unaffiliated with Divide \& Conquer, to form interconnected protrusions, too.

"We are positioning ourselves as the global leaders in this 'disconnection biology," says Grainger, also chief scientific advisor of Medicxi.

Cygnal, meanwhile, has its sights set squarely on blocking peripheral nerve signaling to cells that underpin disease. The company's lead programs are in cancer, but it also has drug candidates in the works for inflammatory bowel conditions in which enteric nerve impulses are thought to contribute to disturbed gut health. Other therapeutic areas - including fibrosis, metabolism and endometriosis - are under consideration as well. The peripheral nervous system "is relevant in all these settings and needs to be decoded," says Cygnal's president and CEO Pearl Huang.

In oncology, most previous nervetargeted drug research has centered on repurposing a common class of heart medicines called $\beta$ blockers. Prompted by dozens of retrospective and observational studies showing that cancer patients who regularly take $\beta$ blockers - ostensibly for high blood pressure or some other cardiovascular problem - typically have better prognoses than patients who do not take the drugs, clinicians recently started prospectively evaluating these agents as potential adjuncts to other anticancer therapies.

In Australia, for example, a team co-led by Erica Sloan, a cancer biologist at the Monash University in Melbourne, tested whether preoperative treatment with propranolol - the world's first $\beta$ blocker, developed in 1964 - could reduce the invasive potential of residual disease cells, and thus lower rates of recurrence, among women undergoing surgery for early-stage breast cancer. Late last year, she and her colleagues reported that one week of $\beta$ blockade leading up to surgery lowered the expression of biomarkers associated with metastasis and promoted immune cell infiltration in the excised tumor tissue.

"We got really lucky," Sloan says of this drug repurposing strategy.

"Propranolol is a way we can do something for patients now." But, she adds, "if we understand the biology, perhaps we can really improve that and do something much better."

That is exactly what Cygnal intends to do. To that end, the company has tapped Sloan as well as Hondermarck, Monje, and other academic researchers including Paul Frenette, a stem cell scientist at the Albert Einstein College of Medicine in New York City, whose lab in 2013 published concrete evidence that nearby nerves are essential to the proliferation of tumors in mice - to serve on its scientific advisory board. In December, the company also funded an invitation-only meeting at the Cold Spring Harbor Laboratory's Banbury Center in New York state to discuss the emerging principles of cancer neuroscience with leading thinkers in the field.

There, and in posters presented at assorted cancer meetings last year, the company described how its scientists are coculturing primary neurons with both tumor and immune cells; using advanced imaging techniques to visualize tumor innervation; manipulating tumor-associated neurons with viral vectors; performing CRISPR-based screens of neuronal genes involved in regulating membrane potential, synapse formation, neurotransmission and axonal guidance; and deploying neurally focused bioinformatics, among other approaches, to find drug targets affecting cancer growth.

Manuel Fankhauser, a scientific consultant to Cygnal and the CSO of the Seerave Foundation, a cancer-focused 